\title{
Pilates for breast cancer: A systematic review and meta-analysis
}

Roberta Costa Espíndula ${ }^{1}$, Gabriella Barbosa Nadas ${ }^{1}$, Maria Inês da Rosa ${ }^{1}$, Charlie Foster ${ }^{2}$, Florentino Cardoso de Araújo ${ }^{3}$, Antonio Jose Grande ${ }^{1,4 *}$

${ }^{1}$ Universidade do Extremo Sul Catarinense, Criciúma, SC, Brazil

${ }^{2}$ Nuffield Department of Population Health, University of Oxford, Oxford, United Kingdom

3President of the Associação Médica Brasileira, São Paulo, SP, Brazil

${ }^{4}$ Universidade Estadual de Mato Grosso do Sul, Dourados, MS, Brazil

Study conducted at Universidade do Extremo Sul Catarinense, Criciúma, SC, Brazil

Article received: 4/1/2017 Accepted for publication: $4 / 3 / 2017$

*Correspondence: Address: Av. Universitária, 1.105 Criciúma, SC - Brazil Postal code: 88806-000 grandeto@gmail.com

\section{SUMMARY}

Introduction: Breast cancer is the leading type of cancer causing death in women worldwide. The incidence of the disease is expected to grow worldwide due to the aging of the population and risk factors related to lifestyle behaviors. Considering the lifestyle of women with breast cancer before or after surgery, pilates exercise may be a complementary intervention additionally to standard treatment.

Objective: To analyze the efficacy of pilates compared to other exercises and to no exercise for women with breast cancer diagnosis.

Method: We searched Medline via Pubmed, Embase via Ovid, Amed via EBSCO, Biosis via Ovid, Lilacs and the Cochrane Library for relevant publications until March 2017. The keywords used were pilates and "breast cancer," and only randomized controlled trials were included. Critical appraisal was done using Risk of Bias Tool and GRADE score for assessing the quality of evidence.

Results: A total of five studies were included in our review. Our results demonstrate that pilates or home-based exercises are better than no exercise in each individual study. We observed significant improvements in the pilates groups compared to home-based exercises. Additionally, in the individual studies, we observed improvements in range of motion, pain and fatigue.

Conclusion: The evidence shows that pilates or home-based exercise should be encouraged to women with breast cancer.

Keywords: motor activity, exercise movement techniques, breast neoplasms, delivery of health care.

\section{INTRODUCTION}

Breast cancer is the leading type of cancer causing death in women worldwide, affecting 1,2 million new cases/year. ${ }^{1}$ The incidence of the disease is expected to grow worldwide due to the aging of the population, risk factors related to lifestyle behaviors such as smoking, poor diet and physical inactivity. ${ }^{2-5}$ Data from the GLOBOCAN 2012, produced by the International Agency for Research on Cancer (IARC), estimate that breast cancer incidence was as high as 1,676,600 new cases in that year. ${ }^{6}$ The prognosis is good when early treatment is started, reaching $88 \%$ of cure rate in five years. ${ }^{1}$

Breast cancer diagnosis can lead a woman's life to consternation, translated into psychophysical suffering, and to an invasive surgery to remove an organ that is symbolic for women and has a negative impact on their quality of life.
Physically, women may have their functional capacity compromised by losing muscular strength, reducing the range of motion and increasing pain. ${ }^{78}$ Socially, women may feel isolation, since breast is a symbol of femininity, sexuality and maternity. ${ }^{9-12}$ With the evolution of better diagnostic methods, early detection was improved, leading to favorable prognosis and, thus, a longer survival rate to the patients..$^{13,14}$

Breast cancer usually occurs in women over 40 years of age but it has recently been more and more diagnosed in younger individuals. ${ }^{15} \mathrm{~W}$ ith this in mind, the social aspects of surgery and chemotherapy are more relevant in younger populations. Women being treated for breast cancer experience many complex situations that require adaptations for the improvement of her physical and emotional structure. ${ }^{16}$ 
Despite providing longer survival with early diagnosis of breast cancer, treatment leaves sequelae with adverse effects such as: influence on functional capacity, fatigue, depression, neuropathic lymphoedema, low immunity and loss of flexibility. All of these effects end up affecting the quality of life. ${ }^{1}$

From the previously described weaknesses that posttreatment for breast cancer provides to patients, the pilates method aims to aid in symptom relief by helping patients regain functionality, improve performance in daily life activities and help reduce fatigue and improve quality of life. ${ }^{8}$ Lastly, pilates exercise may be a complementary intervention, additionally to standard treatment. It is based on the main movements of the body, encouraging the performance of a mind-body connection, using principles such as: breathing, concentration, body alignment, precision, control, rhythm and endurance. ${ }^{17,18}$

The evidence to support the recommendation and widespread use of pilates in women with breast cancer or after surgery has not been well reported yet. Some studies compared the efficacy of pilates compared to other types of exercises on functional capacity, pain and muscular strength showing the benefits of any type of exercise, especially with pilates. Thus, the aim of our study was to analyze the efficacy of pilates compared to other exercises and to no exercise for women with breast cancer diagnosis.

\section{Method}

\section{Data sources and searches}

The protocol for this systematic review was registered at PROSPERO (international prospective register of systemic reviews, http://www.crd.york.ac.uk/PROSPERO/ display_record.asp?ID=CRD42016050360). We searched Medical Literature databases Analysis and Retrieval System Online (Medline) via Pubmed, Excerpta Medical Database (Embase) via Ovid, Allied and Complementary Medicine Database (Amed) via EBSCO, Global health, Biological Abstracts/Reports, Reviews, Meetings (Biosis) via Ovid, as well as the Latin American and Caribbean Health Sciences (Lilacs) and the Cochrane Library for relevant publications until March 2017. All searches were run individually. Additionally, we searched the WHO ICTRP (International Clinical Trials Registry Platform) and ClinicalTrials.gov for completed and ongoing studies.

The search, Cochrane Highly Sensitive Search Strategy, used the following keywords: Pilates AND "Breast Neoplasms" [Mesh] OR "breast cancer." The search was sensitive and did not use study filters. We checked the reference lists of all primary studies included for additional references. We applied no language or publication restrictions.
We included only randomized controlled trials about women with breast cancer or women after breast cancer surgery undergoing treatment and doing pilates exercises in one arm of the study comparing to no exercise or a different type of exercise in the control group.

\section{Study selection}

Two review authors (AJG, GBN) independently assessed all studies identified from the database searches by screening titles and abstracts using the Review Management website Covidence (http://www.covidence.org). We separated potential studies for full-text reading. A third review author (ET) resolved any disagreements. We described the reasons for including and excluding trials.

\section{Data extraction and quality assessment}

Two review authors (AJG, GBN) independently extracted data from the included studies using a standard data extraction form. In this form we extracted information regarding study design, participant description, pilates exercises, control description, each outcomes explored in the studies.

All included studies were assessed for their methodological quality using the Risk of Bias tool from Cochrane Collaboration. The tool is composed of six categories of bias (selection, performance, detection, attrition, reporting and other biases). Items were scored as positive (low risk of bias), negative (high risk of bias) or insufficient information (unclear risk of bias). A figure described the assessment for each study in the results section.

\section{Data synthesis and statistical analysis}

All included studies were organized in Table 1, which summarizes all of the participants' data, all interventions and characteristics of the control group participants, as well as all published outcomes.

A meta-analysis was possible only for the functional capacity outcome. All the tables were organized using Microsoft Excel 2016 and the review was performed using RevMan 5.3 (The Nordic Cochrane Centre, Copenhagen, Denmark).

\section{Results}

The search led to the identification of 34 studies and two additional studies were found by manual search, four of which were excluded as duplicates (Figure 1). A total of 32 studies were assessed based on title and abstract, of which 21 were excluded because they did not fulfill inclusion criteria. Full-text studies were retrieved for 11 titles, of which seven were excluded. 


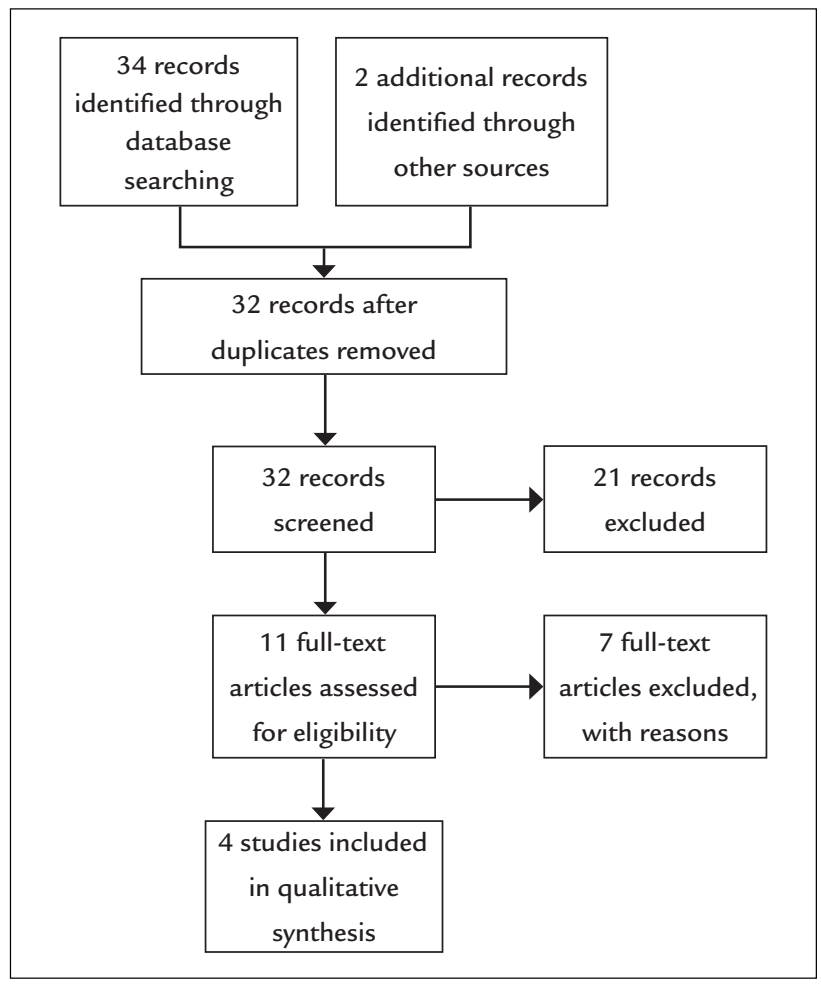

FIGURE 1 Flow chart of systematic review process.

A total of four studies ${ }^{1,8,19,20}$ were included in the review. The number of participants in each study ranged from 26 to 57. Two studies were from Turkey, one from Iran and one from the USA. The mean age of participants in each study ranged from $44.11 \pm 6.19$ to $56.50 \pm 12.97$ years. Most studies included women diagnosed with stage I, II or III breast cancer. Most of the studies prescribed pilates three times per week during 8 weeks and each session lasted 45-60 minutes. All studies had supervision of a physiotherapist.

\section{Methodological quality of included studies}

We used the Risk of Bias tool adopted in Cochrane reviews to analyze the risk of bias in randomized controlled trials. Figure 2 describes each category of bias assessed as low risk, unclear risk and high risk. Random sequence generation was properly described only in two studies; ;,20 other two studies ${ }^{8,19}$ did not provide enough information about how randomization was conducted and were randomized according to baseline values.

Allocation concealment was unclear in three studies, ${ }^{1,8,19}$ which did not provide information on how it was done. Alpozgen et al. ${ }^{20}$ properly described allocation concealment and did not conceal allocation. Blinding of participants, personnel and outcome assessment presented high risk in all studies due to the characteristics

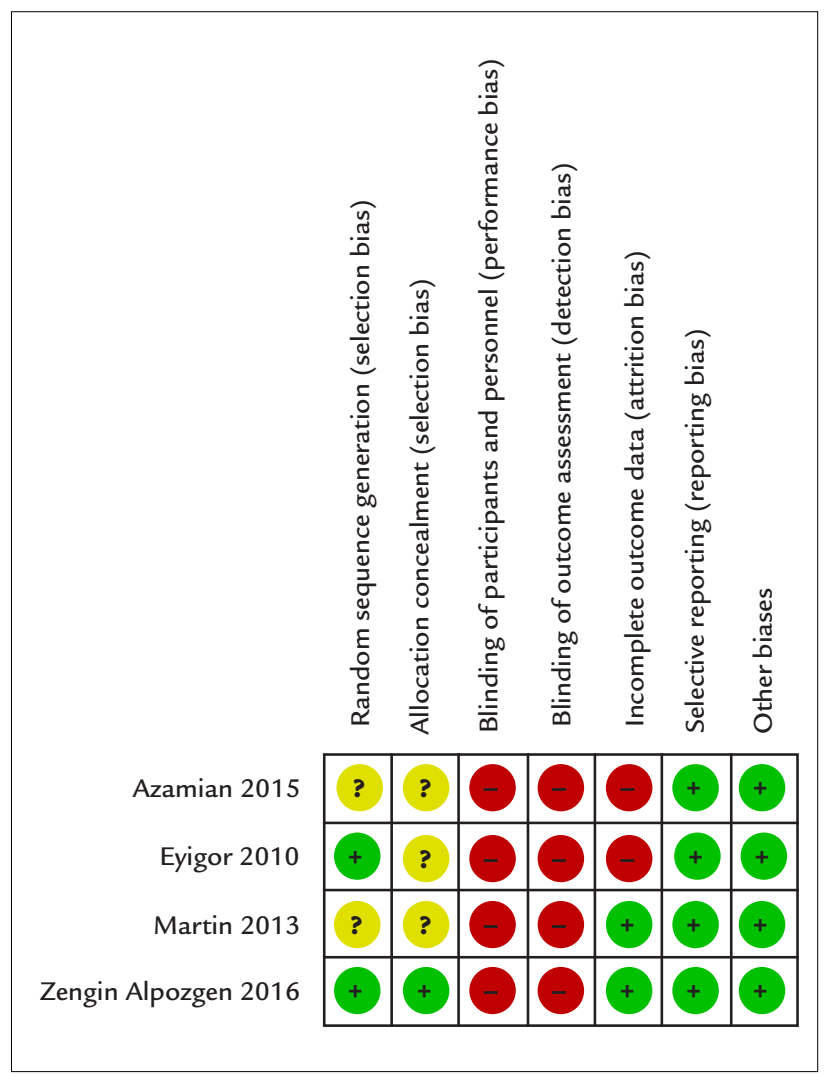

FIGURE 2 Results of the evaluation of each study according to the Risk of Bias tool.

of participants; nevertheless, the outcome assessor could have been blinded.

Two studies ${ }^{1,19}$ had high loss of follow-up and did not properly adjust the statistics for the missing participants, while other two studies ${ }^{8,19}$ did properly adjust the statistical analysis. All studies reported what they proposed in the methods; however, most of them did not present a trial registration number and thus we judged all studies as low risk of bias for selective reporting. In the category Other bias, one study was considered High risk, since the study design was not adequate to answer the research question.

\section{Pilates $\mathrm{x}$ home-based exercise}

Only one comparison was possible in this study. After extracting all data from the primary studies, we observed that two studies ${ }^{1,20}$ compared pilates $\mathrm{x}$ home-based exercises for the outcome functional capacity. Both studies used different scales to measure functional capacity, thus we used standardized mean difference to pool the results. Using random effects meta-analysis we found significant difference between pilates $x$ home-based exercise (two studies, 79 participants; standardized mean difference 


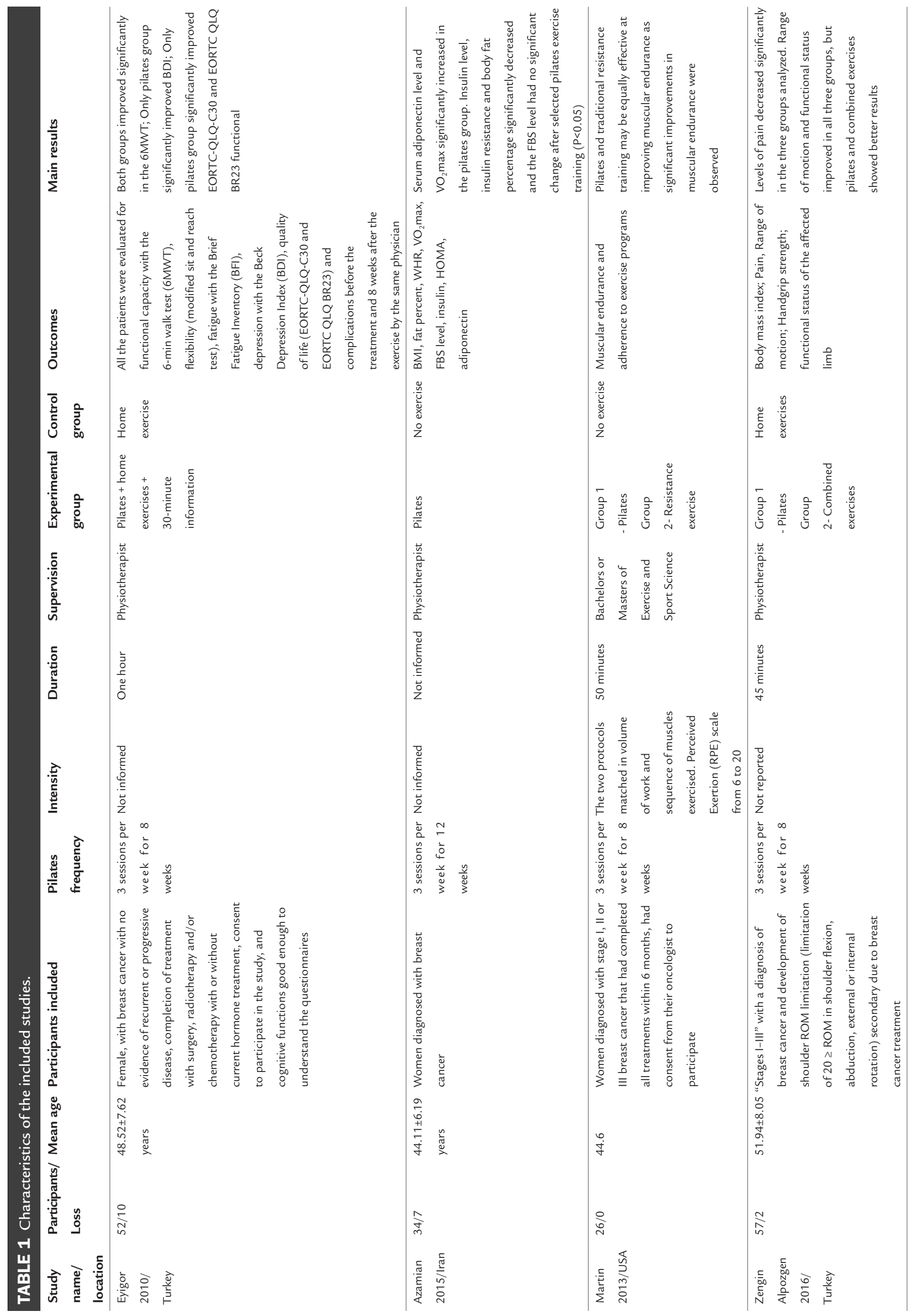


[SMD] 0.99 [95CI 0.51-1.47]; Chi $^{2}$ test 0.71; df $=1 ; \mathrm{p}<0.001$; $I^{2}$ statistic $0 \%$ for functional capacity). Figure 3 presents the forest plot with comparison of pilates $\mathrm{x}$ home-based exercise for functional capacity.

\section{Discussion}

Breast cancer is a chronic degenerative disease with significant global public health importance for women. ${ }^{6}$ The risk factors are well known and improving lifestyle may be a protective factor and reduce the risk of developing the disease. ${ }^{4,5,10,21}$ This is the first systematic review and meta-analysis to specifically investigate and compare the practice of pilates with no exercise and with other exercises for women with breast cancer.

Overall, our results demonstrate that pilates or homebased exercises are better than no-exercise in each individual study. Considering the pooled data for two studies, a meta-analysis was conducted only for the outcome of functional capacity, thus we observed significant improvements in the pilates group compared to home-based exercises. This result was expected: since pilates had a professional monitoring the performance of every exercise, the women had an extra motivation to take pilates training, and had company to exercise. Additionally, in the individual studies we observed improvements in range of motion, pain and fatigue.

There is a systematic review about the methods used in pilates for women's health published in $2015 .{ }^{17}$ Considering pilates and breast cancer, the authors included only two studies. In our systematic review, we found three more RCTs in the literature, and so we can consider it an update of the evidence. We were also able to conduct a meta-analysis on functional capacity. There is growing interest in the topic and new studies are being conducted.

Considering the quality of the studies, improvements are necessary, to perform randomization and allocation concealment, not only in the conduction of the study, but also better described in the study. Due to the type of intervention, blinding was not possible; however, outcome assessors could have been blinded in the studies. Incomplete outcome data was another problem found, with some studies presenting high loss at follow-up.

As for risk of bias assessment, imprecision, inconsistency, indirectness and publication bias, we were able to categorize the evidence based on the GRADE score as low quality. This means that the evidence organized is this systematic review is "very likely that further research would change our estimate of effect or our confidence in it."

The limitations of our research rely on the fact that different protocols of pilates exercises and home-based exercises were used across studies. Heterogeneity was tested but not found across studies. A strong factor is that our review considered all studies around the world. Note that one study was Persian and we had a collaborator translating it.

\section{Conclusion}

The individual studies show that pilates is better than home-based exercises and no-exercise. The studies also showed that home-based exercise or pilates are better than no exercise on fatigue, range of motion, mood and it does not bring risks.

The evidence shows that pilates or home-based exercise should be encouraged for women with breast cancer, and we believe that future studies will succeed in presenting the evidence in a stronger and more reliable manner.

\section{Conflict of interest}

The authors declare no conflict of interest.

\section{Resumo}

Pilates para mulheres com câncer de mama: revisão sistemática e metanálise

Introdução: O câncer de mama é o principal tipo de câncer que causa morte em mulheres em todo o mundo.

\begin{tabular}{|c|c|c|c|c|c|c|c|c|c|c|c|}
\hline \multirow{2}{*}{$\begin{array}{l}\text { Study or } \\
\text { subgroup }\end{array}$} & \multicolumn{3}{|c|}{ Pilates } & \multicolumn{3}{|c|}{ Home-based exercises } & \multirow[b]{2}{*}{ Weight } & Standard mean difference & \multirow{2}{*}{\multicolumn{2}{|c|}{$\begin{array}{c}\text { Standard mean difference } \\
\text { IV, random, } 95 \mathrm{CI}\end{array}$}} & \\
\hline & Mean & SD & Total & Mean & SD & Total & & IV, random, $95 \mathrm{CI}$ & & & \\
\hline Eyigor 2010 & 84.39 & 10.47 & 27 & 75.83 & 10.59 & 15 & $53.8 \%$ & $0.80[0.14,1.46]$ & & - & \\
\hline Zengin & 72.17 & 6.66 & 18 & 60.05 & 11.97 & 19 & $46.2 \%$ & $1.22[0.51,1.92]$ & & & \\
\hline \multicolumn{12}{|l|}{ Alpozgen 2016} \\
\hline Total $(95 \mathrm{Cl})$ & & & 45 & & & 34 & $100 \%$ & $0.99[0.51,1.47]$ & \multirow{2}{*}{$\begin{array}{cc}-2 & -1 \\
\text { Home-based exercises }\end{array}$} & \multirow{3}{*}{ Pilates } & 2 \\
\hline Heterogeneit & $\mathrm{Tau}^{2}=\mathrm{C}$ & $0.00 ; \mathrm{Ch}$ & $i^{2}=0.71$ &,$d f=1(p$ & $p=0.40)$ & $; I^{2}=0 \%$ & & & & & \\
\hline \multicolumn{10}{|c|}{ Test for overall effect $Z=4.04(p<0.0001)$} & & \\
\hline
\end{tabular}

FIGURE 3 Forest plot comparing pilates versus home-based exercises for functional capacity. 
Estima-se que a doença cresça em razão do envelhecimento da população e dos fatores de risco relacionados ao comportamento e estilo de vida. Considerando o estilo de vida das mulheres com câncer de mama antes ou após a cirurgia, o exercício de pilates pode ser uma intervenção complementar, além do tratamento padrão.

Objetivo: Analisar a eficácia do pilates em relação a outros exercícios e a nenhum exercício para mulheres com diagnóstico de câncer de mama.

Método: Buscamos em Medline via Pubmed, Embase via Ovid, Amed via EBSCO, Biosis via Ovid, Lilacs e Cochrane Library publicações relevantes até março de 2017. As palavras-chave utilizadas foram pilates e "câncer de mama"; apenas ensaios clínicos randomizados foram incluídos. A avaliação crítica foi feita com a ferramenta Risk of Bias e escore GRADE para avaliar a qualidade da evidência.

Resultados: Um total de cinco estudos foi incluído nesta revisão. Nossos resultados demonstram que pilates ou exercícios feitos em casa são melhores do que a ausência de exercícios em cada estudo individual. Observamos melhorias significativas no grupo de pilates em comparação com exercícios em casa. Adicionalmente, nos estudos individuais observamos melhorias na amplitude de movimento, dor e fadiga.

Conclusão: A evidência mostra que pilates ou exercícios em casa devem ser encorajados a mulheres com câncer de mama.

Palavras-chave: atividade motora, técnicas de exercício e de movimento, neoplasia de mama, assistência à saúde.

\section{References}

1. Eyigor S, Karapolat H, Yesil H, Uslu R, Durmaz B. Effects of pilates exercises on functional capacity, flexibility, fatigue, depression and quality of life in female breast cancer patients: a randomized controlled study. Eur J Phys Rehabil Med. 2010; 46(4):481-7.

2. Bernardo LM, Abt KL, Ren D, Bender C. Self-reported exercise during breast cancer treatment: results of a national survey. Cancer Nurs. 2010; 33(4):304-9.
3. Metsker J. A healthy lifestyle program for breast cancer survivors: women embracing and loving life. Am J Clin Oncol. 2011; 34(5):552.

4. Schmitz K. Physical activity and breast cancer survivorship. Recent Results Cancer. 2011; 186:189-215.

5. Stan DL, Rausch SM, Sundt K, Cheville AL, Youdas JW, Krause DA, et al. Pilates for breast cancer survivors. Clin J Oncol Nurs. 2012; 16(2):131-41.

6. Ferlay J, Soerjomataram I, Dikshit R, Eser S, Mathers C, Rebelo M, et al. Cancer incidence and mortality worldwide: sources, methods and major patterns in GLOBOCAN 2012. Int J Cancer. 2015; 136(5):E359-86.

7. Magrani do Rosario P, Naumann F, Martin E. The effects of an individual versus a group delivered exercise and counselling intervention on fatigue in breast cancer survivors. J Sci Med Sport. 2011; 14(Suppl. 1):e116-7.

8. Martin E, Battaglini C, Groff D, Naumann F. Improving muscular endurance with the MVe Fitness Chair ${ }^{\mathrm{TM}}$ in breast cancer survivors: a feasibility and efficacy study. J Sci Med Sport. 2013; 16(4):372-6.

9. Finestone S. Meeting the changing emotional and educational needs of breast cancer patients. Psycho-Oncology. 2011; 1:1-2.

10. Aaronson N, Turo AM. Pilates for breast cancer survivors: a guide to recovery, healing, and wellness. New York: Demos Health; 2014.

11. Furzer BJ, Wright KE, Petterson AS, Wallman KE, Ackland TR, Joske DJ. Characteristics and quality of life of patients presenting to cancer support centres: patient rated outcomes and use of complementary therapies. BMC Complement Altern Med. 2013; 13:169.

12. Stan DL, Collins NM, Olsen MM, Croghan I, Pruthi S. The evolution of mindfulness-based physical interventions in breast cancer survivors. Evid Based Complement Alternat Med. 2012; 2012:758641.

13. Luz ND, Lima ACG. Recursos fisioterapêuticos em linfedema pós-mastectomia: uma revisão de literatura. Fisioter Mov. 2011; 24(1):191-200.

14. Panati S, Shahid K, Watson KS, Adair L, Juneja S, Nguyen K, et al. Socioeconomic factors and the use of complimentary and alternative therapies in patients with early stage breast cancer. Cancer Research Conference: 37 th Annual CTRC AACR San Antonio Breast Cancer Symposium San Antonio, TX United States Conference Start. 2014; 75(9 Suppl. 1):P2-12-11.

15. Carneiro Neto JD, Barreto JBP, Freitas NS, Queiroz MA. Câncer colorretal: características clínicas e anatomopatológicas em pacientes com idade inferior a 40 anos. Rev Bras Coloproctol. 2006; 26(4):430-5.

16. Eramo A, Lotti F, Sette G, Pilozzi E, Biffoni M, Di Virgilio A, et al. Identification and expansion of the tumorigenic lung cancer stem cell population. Cell Death Differ. 2008; 15(3):504-14.

17. Mazzarino M, Kerr D, Wajswelner H, Morris ME. Pilates method for women's health: systematic review of randomized controlled trials. Arch Phys Med Rehabil. 2015; 96(12):2231-42.

18. Wells C, Kolt GS, Bialocerkowski A. Defining Pilates exercise: a systematic review. Complement Ther Med. 2012; 20(4):253-62.

19. Jazi AA, Mobarekeh BG, Vismeh Z, Gohar NP. Effect of 12 weeks of selected Pilates exercise training on serum adiponectin level and insulin resistance in female survivors of breast cancer and its role in prevention of recurrence. Scientific J Kurdistan University of Medical Sciences. 2015; 20(5):61-73.

20. Alpozgen AZ, Ozdincler AR, Karanlik H, Agaoglu FY, Narin AN. Effectiveness of Pilates-based exercises on upper extremity disorders related with breast cancer treatment. Eur J Cancer Care (Engl). 2016. [Epub ahead of print]

21. Fong TC, Hoffmann B. Images in clinical medicine. Disappearance of a breast prosthesis during Pilates. N Engl J Med. 2011; 365(24):2305. 